\title{
Applying a global justice lens to health systems research ethics: An initial exploration
}

\author{
Abstract: \\ Recent scholarship has considered what, if anything, rich people owe to poor people to achieve \\ justice in global health and the implications of this for international research. Yet this work has \\ primarily focused on international clinical research. Health systems research is increasingly being \\ performed in developing countries and is essential to reducing global health disparities. This paper \\ provides an initial description of the ethical issues related to priority setting, capacity-building, and the \\ provision of post-study benefits that arise during the conduct of such research. It presents a selection \\ of issues discussed in the health systems research literature and argues that they constitute ethical \\ concerns based on their being inconsistent with a particular theory of global justice (the health \\ capability paradigm). Issues identified include the fact that priority setting for health systems research \\ at the global-level is often not driven by national priorities and that capacity-building efforts frequently \\ utilize one-size-fits-all approaches.
}

Keywords: health systems research; research ethics; global justice; health capability paradigm; bioethics 


\section{INTRODUCTION}

Health research has repeatedly been identified as a vehicle for advancing health in low and middle-income countries (LMICs) and promoting global health equity (CHRD 1990; Ministerial Summit on Health Research 2004; WHO Task Force on HSR 2005; Global Ministerial Forum on Research for Health 2008). The idea that health research should contribute to reducing global health disparities led to a new role for research ethics being proposed-linking research to improved health and research capacity in host communities. In 2000, Benatar and Singer argued that "a new, proactive research ethics ... must ultimately be concerned with reducing inequities in global health and achieving justice in health research and health care" (Benatar and Singer 2000, p. 826). Additional calls to broaden the scope of research ethics to connect health research to justice in global health have been made over the past decade (London 2005; ljsselmuiden et al. 2010; Benatar and Singer 2010).

In response, recent scholarship has started to consider what, if anything, rich people owe to poor people to achieve justice in global health, and the implications of this for the conduct of externally-funded health research in LMICs. Theories of justice from political philosophy establish general obligations for global actors to reduce health disparities between and within countries worldwide (Pogge 2002; Ruger 2009). How external actors from high-income countries who perform international clinical research might discharge their obligation has been articulated in a proposed ethical framework-'research for health justice' (Pratt and Loff 2012). Principles and concepts from the health capability paradigm, a theory of justice that extends the work of Sen and Nussbaum, were applied to derive guidance on how four aspects of international clinical research should be structured: the research target, research capacity strengthening, ancillary care, and post-trial benefits (Pratt and Loff 2012; Pratt et al. 2013). The 'research for health justice' framework describes the specific duties of governments, research funders, sponsors, and researchers to support this form of international clinical research (Pratt and Loff 2012; Pratt et al. 2013). London has also proposed the human development approach, which situates international research within a view of human development derived from theories of justice, but, like 'research for health justice', its requirements are (so far) discussed primarily in the context of clinical research (London 2005). Thus, efforts to develop ethical frameworks that link international research to justice in global health have generally focused on 
clinical research and been limited in scope. Such efforts have not encompassed critical reflection on what is owed in public health or health systems research (HSR) in LMICs. In doing so, they reflect a wider trend in research ethics to primarily focus on ethical issues in clinical research when considering the international context (Hill 2004; Pratt and Loff 2013).

This paper focuses on the ethics of HSR in LMICs. HSR has been defined as the production of new knowledge to improve the performance of health systems (WHO 2009). It describes the components of health systems and their interactions, investigates why health systems do not meet their goals, and/or develops and evaluates interventions to improve health systems' performance (Gilson 2012). The field differs from clinical research in its aims, the nature of the interventions it tests, its focus on the population level rather than the individual level, and its methods (Hyder et al. in press). Unlike clinical research, HSR does not develop medical interventions like drugs or vaccines that are designed to prevent or combat specific diseases. Instead, systems level interventions are tested such as novel way of organizing the delivery of existing medical products of known efficacy, methods of creating demand for health care and services (e.g. conditional cash transfer programs), human resource management strategies for health facilities, or health insurance schemes (Hyder et al. in press). In some instances, systems level interventions may have a particular disease focus such as an intervention developed to improve the delivery of HIV/AIDS care to patients in rural areas. However, as these interventions frequently address aspects of the health system like human resources and financing, they tend to generate impacts across a range of diseases. HSR can also be exploratory or descriptive, which means that no intervention is tested as part of its conduct (Gilson 2012).

The research participants in HSR are commonly groups rather than individual trial participants such as in cluster-based studies (i.e. studies involving large populations like cities and states). Systems level interventions are also frequently allocated to non-human research participants like health facilities or schools (Hyder et al. in press). HSR methods can encompass a wide range of quantitative and/or qualitative methods such as observational studies, cluster trials, economic evaluations, case studies, and participatory action research (Gilson 2012). Controlled trials, where 
randomization occurs at the level of the individual, are not used very often because the real world settings of HSR often create challenges for doing so.

At present, the precise boundaries of HSR are still being mapped and continue to be a source of debate (Bennett et al. 2011; Sheikh et al. 2011; Gilson 2012). For the purposes of this paper, with respect to non-clinical research, HSR should be considered to overlap with public health research, as they share a population focus, and research on the social determinants of health (Hoffman et al. 2012) ${ }^{1}$

HSR ethics is a relatively new and evolving field. Little conceptual or empirical work has been done to characterize the ethical issues inherent to the conduct of HSR in LMICs (Mills 2011). This lack of scholarship is problematic because strong reasons exist for considering the ethics of non-clinical research and, in particular, how such types of international research might contribute to advancing global justice (Pratt and Loff 2013). Nearly all poverty-related medical conditions are amenable to existing treatments (Stevens 2007). However, significant knowledge deficits exist regarding what health system barriers are hindering the delivery of existing treatments in LMICs and what strategies are required for overcoming them (WHO Task Force on HSR 2005). It is unclear how health systems in LMICs can be best organized to promote health equity and to ensure their populations are protected from catastrophic spending on health care and services. HSR and research on the social determinants of health are a high priority in settings where people's minimum health entitlements are not met (WHO Task Force on HSR 2005; WHO Task Force on Research Priorities for Equity in Health and WHO Equity Team 2005). The development of an ethics of HSR is, therefore, important to support such research in LMICs.

\footnotetext{
${ }^{1}$ Some public health research and research on the social determinants of health can be considered HSR. Hoffman (2012, p.

13) states that "[t]he overlap [of HSR] with population health research, however, is less clear, but likely includes research on the public health system and the delivery of non-personal public health programs and interventions. Excluded from health systems research would be population health research's focus on measuring or describing health, examining the determinants of health status and outcomes, and assessing the effects of specific health promotion interventions." Research on the social determinants of health could be considered HSR where it investigates the broader causes (political, economic, etc.) of poor health system performance and targets interventions to these causes, with the aim of enhancing health system functioning.
} 
This paper will contribute to the field by applying a global justice lens to HSR ethics. Toward the aim of linking HSR to justice in global health, it will provide an initial description of ethical issues that relate to three aspects of HSR in LMICs_-priority setting, capacity-building, and post-study benefits-that can connect the enterprise with improved health and research capacity in LMICs. The selection of these three aspects of HSR was informed by a particular theory of global justice, the health capability paradigm, which calls for the reduction of health disparities between and within countries. To identify ethical issues, a literature search was performed that focused on priority setting, capacity-building, and post-study benefits in HSR in LMICs. The problems described in the resultant literature were assessed for their capacity to obstruct progress towards global justice. A subset of the problems were classified as ethical issues because they were inconsistent with the principles and guidance of the health capability paradigm. In carrying out this exercise, we hope to initiate a critical dialogue around the ethics of these specific issues in HSR and stimulate additional thinking on the larger field of HSR ethics.

\section{APPROACH}

\section{Global Justice Perspective: The Health Capability Paradigm}

The global justice perspective that the paper primarily relies upon is the health capability paradigm. It informed the initial choice of topics focused upon in the literature search and was employed to identify ethical issues relating to those topics from within the resultant literature on HSR in LMICs. Before describing the rationale behind the use of this particular theory of justice and how it guided the selection of the aspects of HSR considered by the paper, a brief overview of the health capability paradigm is provided below.

The health capability paradigm is a theory of justice that extends the capability approach to specifically consider health. It relies on three central concepts-prioritarianism, health capabilities, and shortfall inequalities - to describe the ends of justice in global health. The paradigm establishes a universal obligation to efficiently reduce shortfall inequalities in individuals' central health capabilities, 
particularly in countries where the shortfall from the optimal level is large (Ruger 2010a). Central health capabilities refer to individual ability and freedom to achieve certain health functionings (i.e. avoiding preventable morbidity and mortality). Reducing shortfall inequalities in health status for an individual or population refers to diminishing the gap in their health status from the optimal level (the highest level of health attained worldwide in terms of life expectancy, disease prevalence and incidence, and other variables) (Ruger 2010a). This is attained by ensuring that individuals receive the health-related entitlements necessary to achieve their central health capabilities and promote human flourishing. These entitlements include appropriate healthcare goods and services for prevention, diagnosis, treatment, and rehabilitation; social support services; and external environmental conditions-the social norms, relations, and structures within which health-related goods and services are distributed—that support health functioning (Ruger 2010a). Addressing the health needs of those farthest from the optimal level of health is given priority by the health capability paradigm. Achieving justice in global health then means first meeting the health-related entitlements of people who are worst-off in health terms in order to bring them towards an optimal level of health.

To implement its vision of global justice in health, the paradigm calls for a shared health governance mode/ founded upon collective ethical commitment to equity in health (Ruger 2010a). It, thus, operates at a practical level as well as a theoretical level. States have the primary responsibility to foster their citizens' capability to be healthy (Ruger 2008). Specific duties are allocated to specific national and sub-national actors according to the functional requirements principle, which demands that duties be distributed to institutions or actors because the functions that they typically assume make them particularly capable of performing the duties (Ruger 2009). The principle recognizes that institutions and individuals have respective roles in addressing health issues that make them the pragmatic choice to carry out certain duties of justice. National and sub-national actors in the health sector (which includes health research) have specific duties and work together to reduce health shortfalls (Ruger 2010a). Underlying this model of governance are shared moral values and 'voluntary commitment'. Voluntary commitment is defined as the process through which the ethical norm of health equity is internalized at the collective and individual levels. It is the glue holding the system of shared health governance together, leading individuals and institutions to voluntarily make choices and take positive measures to ensure health disparities are reduced worldwide (Ruger 2009). 
Where states are unable to ensure their populations' health capabilities, justice requires that global actors assist states to meet their obligation and build states' capacity to do so on their own (Ruger 2008). This secondary obligation is owed to any LMIC with poor population health, with priority going to the worst-off. Again, specific duties are allocated to specific global actors and institutions according to the functional requirements principle (Ruger 2009). Global actors are public or private entities from outside a particular state and include global health institutions, governments, NGOs, businesses, foundations, and individuals (Ruger 2009).

The health capability paradigm was selected as the global justice perspective used in this paper because it requires the conduct of health research in LMICs, including HSR, and research capacity strengthening, connecting both to the ends of justice in global health that it describes (Pratt and Loff 2012). Relying on capability as the focal variable of justice means that the theory recognizes achieving good health requires the institutional structures and norms that facilitate access to preventative and therapeutic health care and services. This, in turn, reflects that achieving justice entails having an evidence base on not only the efficacy of health care interventions but also the best way to organize the health system that delivers them to populations. The health capability paradigm also establishes a global scope of justice (Ruger 2009). This is important because, without it, states would only owe obligations of justice to their own citizens. Global actors would not have an obligation to help ensure the health capabilities of other populations (by conducting research in LMICs or otherwise). Thus, the health capability paradigm provides grounds for why the conduct of externallyfunded HSR in LMICs is necessary.

The development-oriented nature of Ruger's concept of health justice is another key feature of the paradigm. Achieving health justice is not simply about assisting states that are unable to ensure their populations' health capabilities. It is also about building these states' capacity to meet their populations' needs. The aim of justice is for states to become capable in their own right rather than to be perpetual recipients of rich countries' help. As such, justice consists of building states' capacity to generate their own evidence base on the efficacy of health care, services, and systems (Pratt and Loff 2012). 
Since the health capability paradigm ties HSR in LMICs and research capacity strengthening to its justice agenda, certain aspects of HSR can be identified as being particularly important to the promotion of global health equity. Under the paradigm, HSR in LMICs should promote a reduction in host populations' shortfalls from the optimal level of health (Pratt and Loff 2012). For it to do so, three features of the enterprise are key-priority setting, capacity-building, and post-study benefits. Priority setting has the potential to ensure that HSR identifies and targets the main health system drivers of health shortfalls or gaps experienced by the worst-off in LMICs. Effective priority setting and provision of post-study benefits can deliver health improvements to such individuals and assist weak states to ensure their population's health capabilities. HSR capacity strengthening has the potential to enhance weak states' ability to generate their own evidence on the effectiveness of the health services in their country and, thereby build states' capacity to ensure the health capabilities of their citizens. Thus, the three aspects of HSR considered by this paper were chosen because they can link such research to the ends of justice described by the health capability paradigm.

The health capability paradigm also provides sufficiently detailed guidance on what global health justice entails and how it should be promoted by global actors (direct assistance, capacitybuilding, shared health governance) to facilitate the analysis of HSR practice (Pratt, Zion, and Loff 2012). For example, the paradigm's description of the elements of shared health governance are especially helpful for considering priority setting processes for HSR in LMICs. It can, therefore, be used to identify ethical issues arising in the conduct of HSR in LMICs. (How this was done is described below.) This too makes the health capability paradigm a particularly appropriate global justice lens to utilize for the purposes of the study. ${ }^{2}$

\footnotetext{
${ }^{2}$ We acknowledge that other theories of justice may be useful. Henry Shue and Thomas Pogge's human rights cosmopolitan theories both establish a global scope of justice and require the conduct of HSR in LMICs (Pratt, Zion, and Loff 2012). However, they do not focus solely on health justice and, thus, do not provide as much detail on how it is achieved or the nature of just health governance as the health capability paradigm. We, therefore, felt that the health capability paradigm constituted a strong option to use as a global justice lens to analyze the HSR literature in the selected areas.
} 
Yet there are potential limitations to relying on the health capability paradigm. For example, a weakness of the paradigm for the purposes of our analysis is its lack of consideration of the issue of power. How power is distributed and exercised is an important element of justice (London 2005). Nonetheless, it has been suggested that health capability paradigm is not as sensitive to the interactions, relationships, and power structures contributing to global health disparities as other theories of justice (Mitra 2013). The paradigm only appears to address power disparities between rich and poor countries indirectly through its emphasis on capacity-building and shared decision-making and does not offer direct requirements aimed at reducing power disparities. Relatedly, it also does not explicitly highlight a gendered analysis of justice. Finally, like many other theories of justice, the ability of the health capability framework to be operationalized and measured as it is used and adopted is limited. More in-depth analysis is needed for making this leap from concept to use of indicators of justice, though such work is starting to be done (Ruger 2010b; Wachira and Ruger 2011). .

\section{Identification of Ethical Issues}

To identify ethical issues related to priority setting, capacity-building, and post-trial benefits, literature on HSR in LMICs was gathered by searching four databases-Medline, PubMed, Global Health, and the WHO Global Health Library. The databases were selected for having either a broad focus on health or a more specific focus on global health. ${ }^{3}$ The Alliance for Health Policy and Systems Research website was also reviewed for relevant publications. All searches were limited to English language articles. Once articles in the three domains were collected, they were analyzed for issues of concern in the field of HSR in LMICs. The literature review was supplemented by discussions with health systems researchers present at Johns Hopkins Bloomberg School of Public Health in Baltimore, USA. This included researchers from Botswana, Uganda, the United States, the United Kingdom, and Zambia, who attended a workshop on the ethics of HSR in June 2013 at Johns Hopkins' Berman Institute of Bioethics (Nicotera, 2013).

\footnotetext{
${ }^{3}$ The search included terms such as "health systems" AND "research" AND ("governance" OR "priority" OR "agenda" OR "capacity-building" OR "benefits" OR "policy" OR "collaboration" OR "policy making" OR "health policy" OR "health policies"). Individual articles were then screened for relevance to LMICs.
} 
The paper presents a selection of the problems discussed in the literature and/or noted by health system researchers that we argue constitute ethical issues in HSR in LMICs from a global justice perspective (see Box 1). They are classified as ethical issues due to their being inconsistent with features of the health capability paradigm. These features include the theory's main principles (i.e. justice should be assessed in terms of shortfall inequalities in health capabilities; functional requirements; priority to the worst-off; efficiency), its shared health governance framework, and the general obligations of justice it supports for global actors (i.e. to assist countries to reduce shortfall inequalities in health and to build their capacity to do so). Ethical issues related to priority setting are presented first, followed by ethical issues in capacity-building and then post-study benefits. Since problems are identified as ethical issues based on their failure to align with the health capability paradigm, the paper takes a first step towards developing ethical guidance linking HSR in LMICs to justice in global health.

\section{PRIORITY SETTING}

\section{Global Priorities Drive National Priorities}

Two pertinent concerns were raised regarding the relationship between priority setting for HSR at the global and national levels. First, priority setting for HSR at the global level is often not driven by national priorities. Second, global priorities influence and possibly determine national priorities for HSR in LMICs (Ranson and Bennett 2009; AHPSR 2009). This trend is partly the product of a wider social context in which global and national health priority setting are not on equal footing. Disparities in power and resources result in the health research priorities of high-income countries and their institutions being imposed on poorer countries (Sridhar 2012). The current dynamic can also be attributed to many LMICs failure to put processes in place to generate their own health research priorities, resulting in few national priorities being set and a heavy reliance on global priorities (AHPSR 2009). The lack of demand and capacity for priority setting in LMICs is a significant issue and it will be returned to later in the paper. 
Of course, this problem does not apply to all LMICs. Countries like Tanzania and Brazil have set national health research agendas that identify specific priorities for HSR (NIMR 2006; Ranson and Bennett 2009). Yet, when priority setting exercises have been done at the global level, these country level HSR priorities have not strongly informed them (Ranson and Bennett 2009). In practice, global exercises have incorporated HSR either through the lens of a specific disease or by considering it as a separate category. The latter strategy, for example, was employed by the Ad Hoc Committee on Health Research Relating to Future Intervention Options in 1996 and the WHO Task Force on HSR (established in 2003), which aimed to develop a global research agenda to support the achievement of the Millennium Development Goals (Ranson and Bennett 2009). Nuyens (2007, p. 319) has purported that neither exercise took "full advantage" of existing national research priorities. In fact, priority setting at the global level has tended to be top-down and reliant on a limited consultative process (AHPSR 2009). The extent to which the products of global HSR priority setting exercises reflect country level needs, especially those of LMICs, is unclear (Ranson and Bennett 2009).

The Alliance for Health Policy and Systems Research (2009, p. 3) notes that the "interaction between the national and global levels has received little attention, with no consensus on how to align national and global research agendas and priorities." From a global justice perspective, however, the typical flow of global research priorities influencing and even determining national research priorities is particularly salient, as is LMIC national research priorities' failure to inform global research priorities. The former is inconsistent with the health capability paradigm's allocation of obligations under the functional requirements principle. The theory affirms that the state (national) level is the primary level of responsibility to ensure individuals' health capabilities because states are in the best position to reduce shortfalls between potential and actual health and to develop the health agency of their populations. National and sub-national obligations include the development and maintenance of public health and health care systems (Ruger 2009). Ruger (2012, p. 41) states that the "functioning of health systems is best fulfilled by national and sub-national entities due to the local nature of health service provision, disease prevention, and health promotion programs." Similarly, the fact that HSR can be very context-specific due to the complex and varied nature of health systems means that the role of national and sub-national health authorities in setting HSR priorities is particularly important (Bennett et al. 2011). As these actors are in the best position to set their country's priorities for HSR, it 
creates an obligation of justice for them to do so. Where states are unable to ensure the health capabilities of their populations, global actors have an obligation to assist and work with states to reduce shortfalls in their populations' health from the optimal level, not to take over the entire undertaking. Global actors' role with respect to national priority setting for HSR in LMICs then might be to help organize and implement the process. It would not be to impose their priorities on LMICs or even to necessarily participate in the HSR priority setting processes that they help put in place.

That global priorities drive national priorities for HSR in LMICs is also concerning because the norms underlying global priority setting processes may not be consistent with global health equity (as conceptualized by the health capability paradigm). ${ }^{4}$ The health capability paradigm envisions a world where actors and institutions have internalized commitment to the norm of global health equity (Ruger 2009). All health activities, including priority setting for HSR, should be driven by this norm. Global priority setting for HSR is likely strongly influenced by a global development agenda that emphasizes achieving the Millennium Development Goals (MDGs). HSR has been linked to meeting the MDG targets in WHO reports, at global ministerial summits on health research, and in seven of the twentythree articles on HSR in LMICs and priority setting identified by our literature search (Ministerial Summit on Health Research 2004; WHO Task Force on HSR 2005; Global Ministerial Forum on Research for Health 2008). Although it has been suggested that the MDGs are consistent with capability theory, this is only partially the case. The MDGs reflect a shift in the ideas about the purpose of development and the nature of poverty—namely, that it is to eradicate poverty and that poverty is a multidimensional construct (i.e. comprised of more than just economic disadvantage). These ideas are in accordance with capability theory. However, Sakiko Fukuda-Parr (2011) argues that some elements of the normative ideas inherent to capability theory have become dissociated from the MDG framework. She notes that

[t]he selectivity in transmission from theory to practice is part of a process by which ideas become distorted as they become embraced by institutions (Boas and McNeil 2003). The MDGs whose emergence owed much to the human-centred perspectives on poverty and development have redefined poverty as meeting basic needs, leaving behind elements of

\footnotetext{
${ }^{4}$ Under the health capability paradigm, global health equity is understood as ensuring everyone's health capabilities worldwide and reducing all shortfall inequalities from the optimal level of health.
} 
participation, equality, and empowerment, which are essential to the human development and capabilities and other human-centred perspectives. (Fukuda-Parr 2011, p. 130)

Aside from gender equity, MDG targets do not demonstrate a direct focus on diminishing social and economic disparities between and within countries. They seek to eradicate poverty and establish a minimum or basic level of health globally. In contrast, the health capability paradigm demands that people receive the health-related entitlements necessary for human flourishing (living a life one has reason to value). The aim of justice is then to bring individuals worldwide up to the optimal level of health rather than a basic level. If national priorities for HSR in LMICs are guided by the MDG framework, then they may not promote the norm of health equity endorsed by the health capability paradigm. ${ }^{5}$

Finally, global priority setting processes for HSR that do not include national and sub-national actors and are not informed by their priorities are inconsistent with the health capability paradigm. The theory calls for a system of shared health governance, under which decisions made at the global level reflect the true consensus of global, national, and sub-national actors (as opposed to a "consensus" that primarily reflects the interests of the more powerful actors involved in the decision-making process) (Wachira and Ruger 2011). Decision-making processes should not be top-down or hierarchical, as they can lead to outcomes that reflect the ideologies and goals of the "center rather than local need" (Ruger 2011, p. 41). Where global actors and national actors from high-income countries dictate policy and procedures, there is little involvement of national and sub-national stakeholders from LMICs and little effort is made to achieve the consensus and agreement sought by shared health governance. Decision-making processes ought to be inclusive, ensuring the meaningful participation of a wide range of stakeholders and vulnerable groups (Wachira and Ruger 2011). To adhere to the health capability paradigm's requirements, future global priority setting for HSR must rely on a much broader consultative process and take full advantage of the outputs of national level priority setting for HSR.

\footnotetext{
${ }^{5}$ They, however, may be consistent with other theories of justice, which consider individuals in LMICs to only be owed the means to support a basic level of health rather than an optimal level of health.
} 
The health capability paradigm expects priority setting for HSR at the global level to be informed by national HSR priorities. Where this does not occur, the result is global priorities imposed by donors such as HSR to advance the Millennium Development Goals. Making this a priority has led to a large proportion of HSR in LMICs being focused on service delivery (i.e. identifying better ways for health systems to deliver drug and vaccines or packages of existing interventions and scaling up these delivery mechanisms) related to maternal and child health, HIV/AIDS, TB, and malaria (Ranson and Bennett 2009). There is less support for HSR in LMICs on other health system building blocks such as information technology and governance ${ }^{6}$ or on how to improve health system functioning for vulnerable and marginalized populations within LMICs (Gonzalez-Block, 2004; Adam et al. 2011). This may not be consistent with LMIC needs and/or priorities,

\section{Shortcomings of Priority Setting Methods}

The priority setting methodologies that have been developed for health research are often disease-driven (i.e. Combined Matrix Approach), meaning they are reliant on burden of disease considerations (AHPSR 2009). When employed, these approaches tend to undervalue HSR relative to more disease-focused forms of health research such as basic science, clinical, and epidemiological studies. Ranson and Bennett (2009, p. 27) note that

[m]any health systems research questions stand to provide benefits for multiple different diseases. Linking health systems research questions to specific diseases, rather than seeing them in total, results in these topics being systematically de-prioritized and contributes to the fragmentation of health systems research.

The actual value of HSR topics cannot be adequately measured when limited to the context of specific diseases. Unless they are supplemented or modified, the use of such approaches to priority setting for health research is concerning from a global justice perspective. If global and national priority setting exercises systematically undervalue HSR, it will continue to be identified as a low priority within the research sector. Appropriate levels of funding will not be directed to HSR, which will slow and obstruct progress towards achieving global health equity.

\footnotetext{
${ }^{6}$ Health systems are composed of both hardware (human resources, health services, financing, governance, information technology) and software (norms, values) elements (Sheikh et al., 2011).
} 
An alternative is to set global and national HSR priorities separately from disease-specific research priorities. This requires utilizing different methods of priority setting for HSR, and more interpretive approaches have typically been employed. One example of such an approach is an exercise that was recently carried out by the Alliance for Health Policy and Systems Research, which sought to identify global HSR priorities in select thematic areas (i.e. human resources for health and health system financing) through a process involving policymakers and researchers from twenty-four countries, spanning four regions (Ranson et al. 2010; Ranson, Law, and Bennett 2010). The process consisted of four main steps:

1. Identifying the policy concerns and research priorities at the country and regional level (East Africa, Southeast Asia, Latin America, and Middle East/North Africa) through key informant interviews and literature reviews.

2. Assessing the extent to which current research addressed those priorities.

3. Convening a consultative workshop to develop a list of core research priorities that require urgent attention.

4. Writing up and disseminating the findings and recommendations emerging from the process.

The consultative workshop step in this process is particularly important from a global justice perspective. At this stage, a group of various stakeholders is convened to determine ranking criteria and their respective weights relative to one another and to apply those criteria to rank research questions. As previously discussed, the health capability paradigm would call for this workshop to include a range of stakeholders from the global, national, and sub-national levels in addition to representatives of vulnerable groups in all countries involved. It would further identify requirements for the criteria used to rank research questions. For HSR to be strongly connected to advancing the aims of global justice, the criteria used to rank research questions must include an equity criterion that is heavily weighted relative to other ranking criteria. As an example, in the Alliance for Health Policy and Systems Research priority setting exercise for health systems financing research, 'impact on health and equity' was one of three criteria used to rank priorities and it was weighted twice as heavily as the other two criteria. Three of the top five research priorities that were identified related to health equity (Ranson, Law and Bennett 2010). In the Alliance for Health Policy and Systems Research priority 
setting exercise for human resources for health research, 'impact on health' was one of three criteria used to rank priorities and equity was not explicitly mentioned in any of the priority research questions identified (Ranson et al. 2010). If equity is not used as a ranking criterion, the HSR priorities generated through interpretive approaches may not focus on improving health system conditions for the worst-off (in accordance with the health capability paradigm's prioritarian emphasis) and, therefore, may not strongly promote justice in global health. As there is no standardized method for setting HSR priorities, it is critical that, where interpretive approaches are used, they employ an equity criterion and afford it considerable weight.

Relying on two separate priority setting processes for disease-focused research and HSR further demands the development of a way to integrate disease-focused research priorities and HSR priorities into a single list. The inherent weakness in employing two separate processes is that it gives little indication of the importance HSR priorities to disease-focused research priorities (Ranson and Bennett 2009). Another option is to develop a new approach that combines both processes for use in the future.

Employing interpretive approaches to priority setting for HSR may also prove to be vulnerable to the intrusion of considerations such as politics, economics, and ideology. Such a problem is not described in the literature on HSR priority setting in LMICs, but this is perhaps due to the fact that few global or national processes have been undertaken. Even so, where considerations like the political sensitivity of research findings are relied upon to identify HSR priority topics and questions in LMICs over considerations like impact on health equity and need for research, there is high potential for HSR priority setting's effectiveness at promoting global health justice to be compromised.

\section{Donors' Control the Implementation of Research Priorities}

That priority setting for HSR in LMICs is a donor-driven process was emphasized throughout the literature identified by our search and in our informal discussions with health systems researchers. International organizations and aid agencies currently provide $88 \%$ and $66 \%$ of funding for HSR in low-income countries and middle-income countries respectively (Adam et al. 2011). The majority of 
the literature we found focused on the key role that donors play in the implementation of HSR priorities in LMICs (Gonzalez-Block 2004; Ranson et al. 2010; Adam et al. 2011; Bennett et al. 2011; Sheikh et al. 2011). International donors largely determine what HSR priorities are translated into projects in LMICs through the funding opportunities they offer and their selection of grant proposals to fund.

Bennett et al. (2011) note that current funding mechanisms likely crowd out HSR that is responsive to local needs in favor of HSR to scale-up priority services. New funding agencies are frequently focused on achieving global targets, which leads them to prioritize HSR whose outputs support service scale-up and can be generalized across LMIC contexts. Funding opportunities emphasize programmatic or operational questions on how to expedite the scale up of priority services. They are less likely to focus on deeper structural questions or support participatory action research that engages stakeholders in improving health systems (Bennett et al. 2011). Because funding opportunities for HSR in LMICs are driven by donors and their agendas, they emphasize enhancing the delivery of interventions and services as part of particular disease-control programs rather than the national and sub-national systems and institutions through which such interventions and services are provided (Sheikh et al. 2011). Where donor funding has been made available for health financing research in LMICs, it too has often been poorly aligned with national priorities (Ranson et al. 2010).

Donors tend to ignore national research priorities and country needs in favor of funding global priorities that they likely had a substantial role in designing. This has a huge impact on what HSR is actually conducted in LMICs. Studies confirm that, of the HSR being performed in LMICs, international donors' priorities align most consistently with the research topics being pursued. Gonzalez-Block (2004) found there to be a low emphasis on human resources, equity, and health information systems relative to service delivery by HSR in LMICs. Adam et al. (2011) showed that publications on HSR carried out in LMICs focus on service delivery above other health system components such as human resources and governance. A lack of funding for, and research done on, governance and accountability aspects of health systems in LMICs was further highlighted by the 
Alliance for Health Policy and Systems Research (AHPSR 2008a). Neglect of HSR within fragile states $^{7}$ has been documented as well (AHPSR 2008b).

The dominant role of donors in priority setting for HSR in LMICs is inconsistent with global justice for multiple reasons. First, it means that power is concentrated with one type of global actor rather than shared across HSR stakeholders. This makes it less likely that priority setting for HSR at the global level will reflect the voices of national and sub-national actors from LMICs or reach a genuine consensus, as required by shared health governance. Second, rather than supporting and assisting worst-off states to ensure the health capabilities of their populations, donors disrupt adherence to national research priorities in LMICs by not aligning their funding schemes with them. Instead of respecting national priorities, donors primarily fund HSR in LMICs on a narrow set of questions related to service delivery and scale up. While research on service delivery is necessary, it should not be the only focus of HSR in LMICs, particularly if it does not emphasize improving service delivery for vulnerable and marginalized groups. To ensure the health capabilities of the worst-off, HSR must target the aspects of health systems that function poorly with respect to vulnerable and disadvantaged groups. This will likely vary considerably by country. It may include aspects of service delivery but could also include features of health system financing, information technology, human resources, and governance. "Software" components of the system such as norms, values, gender, and power relations may also be important areas of interest. From the prioritarian perspective of the health capability paradigm, neglect of HSR with fragile state populations is also of concern, as such populations are likely to be some of the worst-off in the world with respect to their health.

\section{CAPACITY-BUILDING}

\section{Funding}

\footnotetext{
${ }^{7}$ Fragile states have been defined by the United Kingdom's Department of International Development as states that are unwilling and/or incapable of delivering basic services to their populations. Fragile states are characterized by a lack of effective political processes to influence the state to meet social expectations, weak institutions and governance systems, endemic violence, and/or limited administrative capacity (AHPSR 2008b).
} 
Most research capacity strengthening programs in LMICs focus on clinical and epidemiological research, leaving little external funding available for capacity strengthening programs in HSR (Bennett et al. 2008). Emphasis on funding long-term capacity development for HSR in LMICs also remains weak amongst funders. The financial regulations and short funding cycles of many bilateral and multilateral funding agencies obstruct commitment to long-term support for HSR capacity-building in LMICs (Trostle and Simon 1992; Bennett et al. 2008). At present, donors mainly support short duration HSR projects in LMICs, though some HSR consortia have been funded over five-year periods (by the United Kingdom's Department of International Development). Many HSR projects in LMICs are funded as short-term consultancies and have an average duration of 14.3 months (Gonzalez Block and Mills 2003; Bennett et al. 2010). Where the attention of staff are diverted to short-term consultancies rather than long-term research collaborations, the development of institutional capacity is undermined (Bennett et al. 2010). Furthermore, development of significant research capacity at individual and institutional levels does not realistically occur through single research projects, especially when their duration is short.

Funding for HSR capacity strengthening in LMICs tends to neglect the systems level. This means that few capacity-building efforts help develop national research systems in LMICs that set HSR priorities, generate financing for such research, establish networks between research organizations, and create links between researchers and decision-makers in health systems (Bennett et al. 2010). What limited efforts are funded generally target the individual and institutional levels. A recent review of the literature on capacity-building interventions for HSR in LMICs noted that training programs (particularly short-courses but also post-graduate level) were the most commonly used capacity development strategy for HSR in LMICs. The review found that interventions targeting the institutional level such as forming partnerships and providing infrastructure support were employed too but less frequently (Bennett et al. 2010). The regulations of many bilateral agencies also call for aid to be tied, which means principal applicants to (research capacity-building) grants must be institutions from high-income countries rather than LMICs (Bennett et al. 2008). ${ }^{8}$

\footnotetext{
${ }^{8}$ This has changed for some aid agencies such as Wellcome Trust, the United Kingdom's Department for International Development, and AusAID, whose research competitions are now untied or permit LMIC applicants to apply.
} 
Since states are assigned the primary obligation to ensure their populations' health capabilities, the health capability paradigm holds that achieving global justice requires building LMICs' capacity to do so. Health research is essential to maintaining the health capabilities of a population, which means justice entails helping LMICs become able to generate their own evidence on the effectiveness of health interventions, services, and systems. External funding to help LMICs develop research capacity, including HSR capacity, is necessary to reduce shortfall inequalities in their populations' health (Ruger 2006; Ruger 2009). HSR capacity strengthening is then a required investment and funding should not disproportionately be allocated to other types of research capacity strengthening by global actors.

Under the health capability paradigm, as global actors fulfill their obligations, LMICs should eventually become able to lead HSR addressing the priority needs for which such research is deemed necessary. This means that research capacity must be strengthened at multiple levels over the longterm, as independent research capacity will take considerable time to develop (Lansang and Dennis 2004). Efforts should build the capacities of individual researchers (junior to senior levels), research institutions, and health research systems in host countries. While building individual capacity to perform HSR is necessary, institutional and systems strengthening are also vital. Systems strengthening, in particular, can serve to provide additional support to research institutions and researchers who conduct HSR and facilitate the determination of national HSR priorities. In effect, global justice calls for long-term capacity-building programs for HSR in LMICs that encompass more than training and collaborations.

\section{Effectiveness}

Another barrier to successful HSR capacity-building in LMICs is a lack of solid evidence regarding what strategies work and in what contexts (Bennett et al. 2010). Evaluation methods need to be developed and studies must be done to evaluate the various capacity-building strategies for effectiveness at the systems, institutional, and individual levels. The strategies that are currently employed in LMICs may not be highly effective because they are unproven. Also of concern is the fact 
that these HSR capacity-building strategies tend to adopt a one-size-fits-all approach (Bennett et al. 2011). Although the literature we identified discusses general strategies for HSR capacity-building and numerous obstacles to achieving gains at the systems, organizational, and individual levels in LMICs, there was very limited description of cases/examples where HSR capacity-building strategies were tailored to respond to the specific needs and obstacles within LMICs at the systems or institutional levels (Varkevisser, Mwaluko, and Le Grand 2001). For example, if financial sustainability after donor support ends and an organizational culture to attract staff are identified as needs at a particular institution, then capacity-building strategies should seek to address these two objectives. Yet Bennett et al. (2010) found that HSR capacity-building programs in LMICs were more likely to adopt "cookie cutter" approaches, even though studies carried out in high-income countries have identified a clear advantage to tailoring HSR capacity-building programs to match specific country or institution needs.

Relying on unproven strategies or one-size-fits-all approaches that evidence suggests have limited effectiveness relative to more tailored approaches is not endorsed by the health capability paradigm. If achieving global justice entails helping LMICs become able to carry out HSR on their own, global actors should utilize capacity-building interventions of high effectiveness. Where they do not, limited resources for capacity-building are being used inefficiently. The health capability paradigm applies efficiency considerations to equity goals. States and global actors should fulfill their obligation to reduce shortfall inequalities in worst-off populations' central health capabilities using as few resources as possible (Ruger 2010a). This means that HSR capacity-building programs should be designed to match specific country or institution needs, enabling LMIC research capacity to be strengthened as efficiently as possible.

POST-STUDY BENEFITS

Weak Knowledge Translation to Policy and Practice 
A key feature of HSR in LMICs is having direct instrumental value by leading to changes in policy and practice. Bennett et al. (2011) note that the belief that HSR should have an effect on policy and practice has led to an emphasis on knowledge translation within the field. Kuruvilla, Mays, and Walt (2007) and Sauerborn, Nitayarumphong, and Gerhardus (1999) re-iterate that one of the main objectives of HSR is to influence policy and identify a commitment to the application of its findings as a defining feature of the field. ${ }^{9}$

Yet a sizeable gap exists in the real world between the evidence generated by HSR and its use in policy and practice in LMICs. Weak knowledge translation and exchange is, therefore, identified as a significant problem (Hyder et al. 2007; El Jardali et al. 2012). It is the main/only area of concern raised in the literature on HSR in LMICs that relates to a lack of post-study benefits for host communities and countries of HSR. This means that the literature we identified primarily focuses on the failure to achieve a fairly linear model of HSR in practice, where knowledge generation is followed by knowledge translation into policy. Yet HSR may not necessarily fit such a model in practice all the time, particularly where it utilizes methodologies like participatory action research. Such linear models might also be far from reality within LMICs. It is, therefore, plausible that additional ethical problems related to post-study benefits arise in HSR in LMICs. ${ }^{10}$

Where a linear model is assumed, numerous barriers to the successful application of HSR evidence to policy and practice in LMICs are discussed in the literature. For the most part, these barriers are associated with three main domains: knowledge of the research-to-policy interface, the research process, and the policymaking process, though specific barriers within the domains may vary by country. A considerable challenge to converting HSR evidence into changes in policy and practice lies in the fact that the process by which translation occurs successfully is not well

\footnotetext{
${ }^{9}$ As such, the following terms have been linked to HSR in the literature-research to policy, knowledge translation and exchange (application of research evidence to policy and practice), research dissemination (pushing out of research evidence by researchers to policymakers and practitioners), research communication (engagement with policymakers and practitioners throughout the research process), and research uptake (stimulating policymakers and practitioners' demand for research). The later three terms represent different strategies to achieve knowledge translation and exchange.

${ }^{10}$ It may be useful to conduct case studies of HSR in LMICs that use participatory action research methods to identify what some of these issues might be.
} 
understood, particularly in LMIC contexts (Orem et al. 2010). There is extensive literature on the research-to-policy interface in high-income countries, but the interface has not been well-examined in LMICs (for health research let alone HSR specifically) (Hyder et al. 2007; Orem et al. 2010).

Research- to-policy models developed through the study of high-income country contexts have limitedly applicability in LMIC contexts due to their having a number of features that are not common to high-income countries-the exaggerated role of donors, a highly chaotic policymaking process, the large role of civil society, and a weak research sector (Orem et al. 2010). There is also a massive diversity in the cultural, political, and economic contexts of different LMICs (Overseas Development Institute, 2004). Considerable more empirical investigation is needed before it becomes clear what research-to-policy strategies work best in LMIC contexts. Although efforts are being made to identify effective strategies (Hyder et al. 2007), at present, HSR stakeholders have a limited understanding of what they need to do to ensure that their findings impact policy and practice in LMIC host countries.

A variety of barriers to translating research to policy have also been described as occurring throughout the HSR process in LMICs. These include (but are not limited to) a lack of: funding, collaboration with policymakers, institutional support, and researchers with the capacity to act as policy entrepreneurs. First, research funders rarely provide support for knowledge translation activities or require a research-to-policy plan as part of grant applications for HSR (El Jardali et al. 2012). Second, health systems researchers from Asia and the Eastern Mediterranean region describe a lack of collaboration and dialogue with policymakers throughout the research process in their countries, including during priority-setting (Jonsson et al. 2007; El Jardali et al. 2012). In a recent study of health systems researchers from the Eastern Mediterranean region, only $16 \%$ of those surveyed said that they interacted with policymakers when selecting their research question and only $19.8 \%$ reported involving policymakers in any phase of their research project (El Jardali et al. 2012). Failure to consult with LMIC policymakers (national and sub-national) means that there is no guarantee health research, including HSR, addresses questions that are relevant to them (Lairumbi et al. 2008). Policymakers are less likely to use evidence from studies that seek to answer questions that they do not find relevant. 
Third, research institutions in both high-income countries and LMICs fail to support researchto-policy activities for HSR in LMICs. They do not have systems and structures in place to promote research uptake such as research-to-policy units (Knezovich 2012; El Jardali et al. 2012). The lack of formal structures makes it hard to maintain and nurture relationships with local policymakers and practitioners beyond the life of single research projects in LMICs (Lairumbi et al. 2008). Additionally, most institutions do not have policies in place that create incentives for health systems researchers to carry out research-to-policy activities in LMICs or elsewhere. Criteria for promotions are linked to writing publications and being awarded grants rather than getting research into policy and practice in host countries (El Jardali et al. 2012). As a result, most health systems researchers spend the majority of their time doing the former two activities and have little time left for the latter (Knezovich 2012).

Fourth, the failure of health systems researchers to serve as policy entrepreneurs and to develop the capacities required to do so can impede the uptake of their evidence by policymakers in LMICs. Health systems researchers commonly do not see knowledge translation or dissemination to policymakers as their responsibility, which diminishes the flow of information/evidence to policymakers in LMICs (Jonsson et al. 2007; Knezovich 2012). Where health system researchers lack an understanding of the policymaking process in a given LMIC, they will not have the technical capacity to use HSR evidence to influence policy in that country effectively (Hyder et al. 2011). Where health systems researchers have a poor ability to communicate the relevance of their research findings to policymakers in LMICs, they are also unlikely to convince policymakers that their findings should be incorporated into an existing or new policy (Jonsson et al. 2007).

Barriers to translating HSR to policy were described as occurring in the policymaking process in LMICs as well. Many LMICs lack the "research culture" that is required for evidence-based policymaking (Hyder et al. 2011). Cultural attitudes and views on research do not identify research evidence as feeding into the policy cycle (Jonsson et al. 2007). As a result, policymakers have little regard for the value of evidence and minimal interest in the outputs of academic research, which, in turn, leads to low demand for HSR by policymakers in LMICs (Lairumbi et al. 2008; El Jardali et al. 2012). Given that political factors are more likely to drive policymaking, they affect the uptake of 
research evidence. Here, factors like ideology, budget considerations, electoral considerations, and political sensitivity of research findings may serve to inhibit the translation of HSR to policy in LMICs (Hyder et al. 2011; El Jardali et al. 2012). Lack of coordination between different ministries and health providers reflects an institutional barrier to information/evidence moving between key actors (Hyder et al. 2011; El Jardali et al. 2012). As a result, health systems researchers may disseminate their evidence to one party without that information making its way to up to national level actors or down to district level actors in their host countries. Finally, where local policymakers lack the capacity to interpret research results and use them appropriately, translating HSR to policy in LMICs will be impeded (Tomson et al. 2005; Hyder et al. 2011; Uneke et al. 2010).

A weak HSR-to-policy interface in LMICs and its underlying contributing factors are all of ethical concern from a global justice perspective. The health capability paradigm calls for research to, as a priority, contribute to ensuring the health capabilities of the worst-off. Health capabilities consist of having not only basic health interventions and services but also the institutional structures (health systems), agency, and norms that facilitate access to them (Ruger 2010b). HSR must, therefore, advance the element of health capabilities to which it is primarily positioned to contribute: improved health systems. It ought to ensure that interventions that effectively target different components of the health system (e.g. services, financing, human resources, governance) are implemented post-study and that evidence of good quality is used to guide health policies at sub-national and/or national levels in LMICs. Where HSR identifies strong evidence and that evidence does not inform policy or practice, such research does not meet the demands of justice under the health capability paradigm. Aspects of the research and policymaking processes that inhibit the translation of HSR to policy are then of ethical concern because they obstruct the development of better health systems in LMICs, which are essential to the achievement of global justice in health. Lack of evidence on what researchto-policy strategies work in different contexts also raises ethical concern because it promotes an inefficient use of resources. Better understanding of the research-to-policy interface in LMICs and what approaches can successfully translate HSR evidence into policy is needed so that resources directed to such efforts are used more efficiently. 


\section{DISCUSSION}

This paper contributes to the sparse literature on the ethics of HSR by providing an initial exploration of the ethical issues within three areas of HSR-priority setting, capacity-building, and post-study benefits-from a global justice perspective. The health capability paradigm was used to inform the initial identification of these three areas of HSR. It was further employed as a tool of analysis to identify the subset of the problems arising in relation to priority setting, capacity-building, and post-study benefits in HSR in LMICs that impede advancement towards justice in global health. It is clear from this analysis that the current reality of these processes is not consistent with the requirements of global justice described by the health capability paradigm. In fact, much of status quo might be posing barriers to furthering the goals of equity and social justice. The analysis also reveals that, while the current state may not be optimal, pathways for change to promote justice can be delineated (with further analysis) since the first step in such a process-identification of barriers-can be achieved through the type of exploration shown in this paper. Concerns around current priorities, funding, and implementation of HSR in LMICs are not only operational issues but, as this paper demonstrates, truly ethical concerns that are worthy of global attention.

This paper has argued that numerous equity-oriented ethical issues relating to priority setting, capacity-building, and post-study benefits are described in the HSR literature focused on LMICs (see Box 1). Some of these ethical issues are clearly related to one another. For example, the lack of HSR capacity-building at the systems level in LMICs (due to little national and donor funding) affects both priority setting and post-study benefits in HSR. Without capacity-building directed at the systems level, LMICs do not develop and implement priority setting mechanisms. This deters the identification of national priorities for HSR, which makes it difficult for priority setting at the global level to be informed by LMIC needs. The absence of national HSR priorities in LMICs also inhibits HSR from having an impact on policy and practice in host countries because the HSR projects that receive funding are less likely to investigate research questions that are relevant to local policymakers and health service providers. 
Global priorities' influence on national priorities for HSR in LMICs and the donor-driven nature of the implementation of HSR priorities also impact the capacity of HSR to generate post-study benefits in LMICs. They each reduce the likelihood that what little HSR evidence is generated will be taken up and used by policymakers in LMICs. Local stakeholders' lack of ownership of the HSR agenda results in research being performed that has little relevance to its host country contexts (Jonsson et al. 2007; El Jardali et al. 2012). Thus, the equity-oriented ethical issues are not only complex themselves but also inter-twined.

It is acknowledged that some of the ethical issues listed in Box 1 may not be unique to HSR. Priority setting, capacity-building, and post-study benefits are features of other types of health research performed in LMICs and similar ethical issues may arise during their conduct. A failure to make drugs proven efficacious available in host communities and countries post-trial has been documented in international clinical research (Kass and Hyder 2001; Annas and Grodin 1998). Like HSR, poor translation of findings into practice in LMICs is a problem for international clinical research. However, at present, there is little, if any, analysis of what ethical issues are experienced as part of priority setting, capacity-building, and provision of post-study benefits in HSR in LMICs (and, to some extent, in international clinical research) and, thus, they deserve the attention provided here. It is also the case that this paper has not covered all of the aspects of HSR that might connect the enterprise to a broader justice agenda. The selection of three aspects was meant to start this ethical analysis, but additional work on other aspects of HSR will be important in the future.

Another limitation of this study is that the literature review was restricted to English language articles. It is possible that additional ethical issues relating to priority setting, capacity-building, and post-study benefits might have been described in non-English articles on HSR in LMICs. We would note, however, that the volume of non-English literature may be quite low. For example, the Medline search that was performed for this study only identified three non-English articles (written in Spanish).

Ultimately, this paper has shown that ethical issues in priority setting, capacity-building, and post-study benefits occur during the conduct of HSR in LMICs. Even so, much more conceptual and empirical work is needed if research ethics is going to connect externally-funded HSR in LMICs to 
justice in global health. On the empirical side, more investigation of the ethical issues in each of the three domains discussed in this paper is required. For instance, case studies of how HSR priority setting occurs at the global and national levels in LMICs and its relationship to funders, consortia, and researchers' selection of funding opportunities and research questions might usefully be carried out. Case studies of different funders' approaches to capacity-building in LMICs might be undertaken as well. Conceptual work should be performed to identify specific obligations of justice to address the various ethical issues related to priority setting, capacity-building, and post-study benefits in HSR in LMICs and to justify their allocation to specific research actors (governments, funders, sponsors, investigators). Beyond bioethicists doing research, advances in the ethics of HSR will also be driven by greater dialogue amongst ethicists, researchers, policymakers, and donors. Such dialogue can be generated through workshops on HSR ethics and by sessions at upcoming conferences. It is hoped that this paper will stimulate a global discourse that pays greater attention to the ethics of HSR and specifically focuses on exploring how the conduct of HSR can contribute to the reduction of health disparities, particularly those between rich and poor countries. 


\section{REFERENCES}

Adam, Taghreed, Saad Ahmad, Maryam Bigdeli, Abdul Ghaffar, and John-Arne Røttingen. 2011. Trends in Health Policy and Systems Research over the Past Decade: Still Too Little Capacity in Low-Income Countries. PLoS One 6 (11): e27263.

Alliance for Health Policy and Systems Research (AHPSR). 2008a. Neglected Health Systems Research: Governance and Accountability. Geneva: WHO.

Alliance for Health Policy and Systems Research (AHPSR). 2008b. Neglected Health Systems Research: Health Policy and Systems Research in Conflict-Affected Fragile States. Geneva: WHO.

Alliance for Health Policy and Systems Research (AHPSR). 2009. Priority Setting for Health Policy and Systems Research. Geneva: WHO.

Benatar, Solomon R., and Peter A. Singer. 2000. A New Look at International Research Ethics. British Medical Journal 321: 824-826.

Benatar, Solomon R., and Peter A. Singer. 2010. Responsibilities in International Research: A New Look Revisited. Journal of Medical Ethics 36: 194-197.

Bennett, Sara, Taghreed Adam, Christina Zarowsky, Viroj Tangcharoensathien, Kent Ranson, Tim Evans, and Anne Mills. 2008. From Mexico to Mali: Progress in Health Policy and Systems Research. The Lancet 372: 1571-1578.

Bennett, Sara, Irene Akua Agyepong, Kabir Sheikh, Kara Hanson, Freddie Ssengooba, and Lucy Gilson. 2011. Building the Field of Health Policy and Systems Research: An Agenda for Action. PLoS Medicine 8: e1001081. 
Bennett, Sara, Ligia Paina, Christine Kim, Irene Agyepong, Somsak Chunharas, Di McIntyre, and Stefan Nachuk. 2010. What Must be Done to Enhance Capacity for Health Systems Research? Available at $h$ ttp://www.rockefellerfoundation.org/uploads/files/c4ccb675-f6f847de-8552-e032d4c3fc20.pdf, accessed 14 July 2013.

Commission on Health Research for Development. 1990. Health Research: Essential Link to Equity in Development. Oxford: Commission on Health Research for Development.

El-Jardali, Fadi, John N. Lavis, Nour Ataya, Diana Jamal, Walid Ammar, and Saned Raouf. 2012. Use of Health Systems Evidence by Policymakers in Eastern Mediterranean Countries: Views, Practices, and Contextual Influences. BMC Health Services Research 12: 200.

Fukuda-Parr, Sakiko. 2011. Theory and Policy in International Development: Human Development and Capability Approach and the Millennium Development Goals. International Studies Review 13: 122-132.

Gilson, Lucy. 2012. Health Policy and Systems Research: A Methodology Reader. Geneva: Alliance for Health Policy and Systems Research.

Glantz, Leonard, George J. Annas, Michael A. Grodin, and Wendy K. Mariner. 1998. Research in Developing Countries: Taking 'Benefit' Seriously. Hastings Center Report 28: 38-42.

Global Ministerial Forum on Research for Health. 2008. Bamako Call to Action on Research for Health, Bamako, Mali.

Gonzalez-Block, Miguel A. 2004. Health Policy and Systems Research Agendas in Developing Countries. Health Research Policy and Systems 2: 6.

Gonzalez-Block, Miguel A., and Anne Mills. 2003. Assessing Capacity for Health Policy and Systems Research in Low and Middle Income Countries. Health Research Policy and Systems 1: 1. 
Hill, Peter. 2004. Ethics and Health Systems Research in 'Post'-Conflict Situations. Developing World Bioethics 4: 139-153.

Hoffman, Steven J., John-Arne Røttingen, Sara Bennett, John N. Lavis, Jennifer S. Edge, and Julio Frenk. (2012). Background Paper on Conceptual Issues Related to Health Systems Research to Inform a WHO Global Strategy on Health Systems Research. Accessed at http://www.who.int/alliance-hpsr/alliancehpsr_backgroundpaperhsrstrat1.pdf, 14 July 2013.

Hyder, Adnan A., Gerald Bloom, Melissa Leach, Shamsuzzoha B. Syed, David H. Peters, and Future Health Systems: Innovations for Equity. 2007. Exploring Health Systems Research and its Influence on Policy Processes in Low Income Countries. BMC Public Health 7: 309.

Hyder, Adnan A., Adrijana Corluka, Peter J. Winch, Azza El-Shinnawy, Harith Ghassany, Hossein Malekafzali, Meng-Kin Lim, Joseph Mfutso-Bengo, Elsa Segura, and Abdul Ghaffar. 2011. National Policy-makers Speak Out: Are Researchers Giving Them What They Need? Health Policy and Planning 26: 73-82.

Hyder, Adnan A., Abbas Rattani, Carleigh Krubiner, Abdulgafoor M. Bachani, and Nhan T. Tran. 2013. Ethical Review of Health Systems Research in Low and Middle Income Countries: A Conceptual Exploration. American Journal of Bioethics, in press.

ljsselmuiden, Carel B., Nancy E. Kass, Nelson K. Sewankambo, and James V. Lavery. 2010. Evolving Values in Ethics and Global Health Research. Global Public Health 5: 154-163.

Jönsson, Kristina, Göran Tomson, Christer Jönsson, Sengchanh Kounnavong, and Rolf Wahlström. 2007. Health Systems Research in Lao PDR: Capacity Development for Getting Research into Policy and Practice. Health Research and Policy Systems 5: 11.

Kass, Nancy E., and Adnan A. Hyder. 2001. Attitudes and Experiences of U.S. and Developing 
Country Investigators Regarding U.S. Human Subjects Regulations. In Ethical and Policy Issues in International Research: Clinical Trials in Developing Countries, volume II, B1-B155. Bethesda, MD: National Bioethics Advisory Commission.

Knezovich, Jeff. (2012). The Challenges of Research Uptake. Available at http://www.drussa.net/index.php?option=com_content\&view=article\&id=1545\%3Athechallenges-of-research-uptake-systemic-institutional-and-individualbarriers\&catid=206\%3Aword-of-the-moment\&ltemid=299\&lang=en, accessed 14 July 2013.

Kuruvilla, Shyama, Nicholas Mays, and Gill Walt. 2007. Describing the Impact of Health Services and Policy Research. Journal of Health Services Research \& Policy 12: 23.

Lairumbi, Geoffrey Mbaabu, Sassy Molyneux, Robert W. Snow, Kevin Marsh, Norbert Peshu, and Mike English. 2008. Promoting the Social Value of Research in Kenya: Examining the Practical Aspects of Collaborative Partnerships Using an Ethical Framework. Social Science and Medicine 67: 734-747.

Lansang, Mary Ann, and Rodolfo Dennis. 2004. Building Capacity in Health Research in the Developing World. Bulletin of the World Health Organization 82: 764-770.

London, Alex J. 2005. Justice and the Human Development Approach to International Research. Hastings Center Report 35: 24-37.

Mills, Anne. 2011. Health Policy and Systems Research: Defining the Terrain; Identifying the Methods. Health Policy and Planning, doi: 10.1093/heapol/czr006.

Ministerial Summit on Health Research. 2004. The Mexico Statement on Health Research, Mexico City. 
Mitra, Agomoni Ganguli. (2013). A Social Connection Model for International Clinical Research. American Journal of Bioethics 13: W1-W3.

National Institute for Medical Research (NIMR). 2006. Tanzania Health Research Priorities, 20062010. Dar es Salaam, Tanzania: NIMR.

Nicotera, Bobbi. 2013. Berman Institute Hosts Global Bioethics Week. Available at http://www.jhsph.edu/research/centers-and-institutes/johns-hopkins-international-injuryresearch-unit/news/Berman_Institute_Hosts_Global_Bioethics_Week, accessed 5 August 2013.

Nuyens, Yvo. 2007. Setting Priorities for Health Research: Lessons from Low- and Middle-Income Countries. Bulletin of the World Health Organization 85: 319-320.

Orem, Juliet N, David K Mafigiri, Bruno Marchal, Freddie Ssengooba, Jean Macq, and Bart Criel. 2010. Research, Evidence and Policymaking: The Perspectives of Policy Actors on Improving Uptake of Evidence in Health Policy Development and Implementation in Uganda. BMC Public Health 12:109.

Overseas Development Institute. 2004. The RAPID Framework for Assessing Research-Policy Links. Available at $h$ ttp://www.odi.org.uk/sites/odi.org.uk/files/odi-assets/eventsdocuments/2764.pdf, accessed 17 July 2013.

Pogge, Thomas. 2002. World Poverty and Human Rights: Cosmopolitan Responsibilities and Reforms. Cambridge: Polity Press.

Pratt, Bridget, and Bebe Loff. 2012. A Framework to Link International Clinical Research to the Promotion of Justice in Global Health. Bioethics, doi: 10.1111/bioe.12009

Pratt, Bridget, and Bebe Loff. 2013. Linking International Research to Global Health Equity: The 
Limited Contribution of Bioethics. Bioethics, 27: 208-214.

Pratt, Bridget, Deborah Zion, and Bebe Loff. 2012. Evaluating the Capacity of Theories of Justice to Serve as a Justice Framework for International Clinical Research. American Journal of Bioethics 12: 30-41.

Pratt, Bridget, Deborah Zion, Khin Maung Lwin, Phaik Yeong Cheah, Francois Nosten, and Bebe Loff. 2013. Ancillary Care: Theory and Practice in International Clinical Research. Public Health Ethics, doi: 10.1093/phe/pht015.

Ranson, Michael K., and Sara Bennett. 2009. Priority Setting and Health Policy and Systems Research. Health Research Policy and Systems 7: 27.

Ranson, Michael K., Mickey Chopra, Salla Atkins, Mario Roberto Dal Poz, and Sara Bennett. 2010. Priorities for Research into Human Resources for Health in Low and Middle-Income Countries. Bulletin of the World Health Organization 88: 435-443.

Ranson, Kent, Tyler J. Law, and Sara Bennett. 2010. Establishing Health Systems Financing Research Priorities in Developing Countries Using a Participatory Methodology. Social Science and Medicine 70: 1933-1942.

Ruger, Jennifer Prah. 2006. Ethics and Governance of Global Health Inequalities. Journal of Epidemiology and Community Health 60: 998-1002.

Ruger, Jennifer Prah. 2008. Normative Foundations of Global Health Law. Georgetown Law Journal 96: $423-443$.

Ruger, Jennifer Prah. 2009. Global Health Justice. Public Health Ethics 2: 261-275.

Ruger, Jennifer Prah. 2010a. Health and Social Justice. Oxford: Oxford University Press. 
Ruger, Jennifer Prah. 2010b. Health Capability: Conceptualization and Operationalization. American Journal of Public Health 100: 41-49.

Ruger, Jennifer Prah. 2011. Shared Health Governance. American Journal of Bioethics 11: 32-45.

Ruger, Jennifer Prah. 2012. Global Health Justice and Governance. American Journal of Bioethics 12: $35-54$

Sauerborn, R., S. Nitayarumphong, and A. Gerhardus. 1999. Strategies to Enhance the Use of Health Systems Research for Health Sector Reform. Tropical Medicine and International Health 4: 827-835.

Sheikh, Kabir, Lucy Gilson, Irene Akua Agyepong, Kara Hanson, Freddie Ssengooba, and Sara Bennett. 2011. Building the Field of Health Policy and Systems Research: Framing the Questions. PLoS Medicine 8: e1001073.

Sridhar, Devi. 2012. Who Sets the Global Health Research Agenda? The Challenge of Multi-Bi Financing. PLoS Medicine 9: e1001312.

Stevens, Philip. 2007. Fighting the Diseases of Poverty. London: International Policy Press.

Tomson, G., C. Paphassarang, K. Jönsson, K. Houamboun, K. Akkhavong, and R. Wahlström. 2005. Decision-makers and the Usefulness of Research Evidence in Policy Implementation—A Case Study from Lao PDR. Social Science and Medicine 61: 1291-1299.

Trostle, James, and Jonathon Simon. 1992. Building Applied Health Research Capacity in LessDeveloped Countries: Problems Encountered by the ADDR Project. Social Science and Medicine 35: 1379-1387. 
Uneke, Chigozie J., Abel E. Ezeoha, Chinwendu D. Ndukwe, Patrick G. Oyibo, and Friday Onwe. 2010. Development of Health Policy and Systems Research in Nigeria: Lessons for Developing Countries' Evidence-Based Health Policy Making Process and Practice. Healthcare Policy 6: e109-e126.

Varkevisser, Corlien M., Gabriel M.P. Mwaluko, and Amanda Le Grand. 2001. Research in Action: The Training Approach of the Joint Health Systems Research Project for the Southern African Region. Health Policy and Planning 16: 281-291.

Wachira, Catherine, and Jennifer Ruger. 2011. National Poverty Reduction Strategies and HIV/AIDS Governance in Malawi: A Preliminary Study of Shared Health Governance. Social Science and Medicine 72: 1956-1964.

WHO. (2009). Scaling Up Research and Learning for Health Systems: Now is the Time. Report of a High Level Task Force (presented and endorsed at the Global Ministerial Forum on Research for Health 2008), Bamako, Mali. Available at http://www.who.int/rpc/publications/scaling_up_research/en/index.html, accessed 16 September 2013.

WHO Task Force on Health Systems Research. 2005. The Millennium Development Goals will not be Attained Without New Research Addressing Health System Constraints to Delivering Effective Interventions. Geneva: WHO.

WHO Task Force on Research Priorities for Equity in Health, and the WHO Equity Team. 2005. Priorities for Research to Take Forward the Health Equity Policy Agenda. Bulletin of the World Health Organization 83: 948-53. 


\section{Box 1: Ethical issues in HSR}

\section{Priority setting}

1. Priority setting for HSR at the global level is often not driven by national priorities.

2. Global priorities influence and possibly determine national priorities for HSR in LMICs.

3. Disease-specific health research priority setting methods devalue HSR.

4. Interpretive priority setting methods for HSR may not utilize an equity criterion.

5. Donors exert substantial control over the selection and implementation of HSR priorities in LMICs.

\section{Capacity-Building}

1. Funding for health research capacity-building in LMICs is directed primarily to clinical and epidemiological research at the expense of HSR.

2. Funding for HSR capacity-building in LMICs does not strongly support long-term activities or interventions that target the systems level.

3. Capacity-building efforts for HSR in LMICs frequently utilize strategies of limited effectiveness (e.g. one-size-fits-all approaches).

\section{Post-study benefits}

1. Translation of HSR evidence into policy and practice in LMICs is poor.

2. Relationship between researchers, donors, and policymakers sub-optimal for supporting the development of clear plans for provision of benefits to LMICs (especially prior to start of research). 


\section{University Library}

\section{- M M N E R VA A gateway to Melbourne's research publications}

Minerva Access is the Institutional Repository of The University of Melbourne

Author/s:

Pratt, B;Hyder, AA

Title:

Applying a Global Justice Lens to Health Systems Research Ethics: An Initial Exploration

Date:

2015-03-01

Citation:

Pratt, B. \& Hyder, A. A. (2015). Applying a Global Justice Lens to Health Systems Research Ethics: An Initial Exploration. KENNEDY INSTITUTE OF ETHICS JOURNAL, 25 (1), pp.35-66. https://doi.org/10.1353/ken.2015.0005.

Persistent Link:

http://hdl.handle.net/11343/56567 